\title{
A Composite Indicator for Supply Chain Performance Measurement: A Case Study in a Manufacturing Company
}

\author{
R. Oliveira ${ }^{1 *}$, C. Cubo ${ }^{1}$, R. Estrada ${ }^{1}$, A. C. Fernandes ${ }^{1}$, P. Afonso ${ }^{1}$, M. S. Carvalho ${ }^{1}$, P. Sampaio ${ }^{1}$, \\ J. Roque ${ }^{2}$, M. Rebelo ${ }^{2}$ \\ ${ }^{1}$ Department of Production Systems, ALGORITMI Research Centre, University of Minho, Braga, Portugal \\ ${ }^{2}$ Bosch Car Multimedia, Braga, Portugal \\ *(id6911@alunos.uminho.pt)
}

\begin{abstract}
This paper proposes a methodology to develop and implement a Composite Indicator (CI) to measure the performance of Supply Chain processes. It reflects the aggregation of individual measures, related to the same process, with a weighted average, in order to assess the global performance in terms of both efficiency and effectiveness. Through a case study in a manufacturing company, a concept validation was performed by implementing the methodology in the Return process of the Supply Chain. The results showed that the combination between a Composite Indicator and a Business Intelligence tool provides a better understanding of the overall performance of a given process, facilitating also the identification of root causes. This paper aims to contribute to the supply chain performance management research field, proposing a methodology to implement a Composite Indicator, which is a topic insufficiently explored in the existent literature.
\end{abstract}

Keywords - Composite Indicator, Efficiency and Effectiveness, Performance Measurement, Quality Management, Return process, Supply Chain Management.

\section{INTRODUCTION}

In order to guarantee greater customer satisfaction and promote competitiveness, companies that have implemented a Quality Management System, are now more aware that business competition is passing gradually to the supply chain management level [1], [2], [3].

The success of those management systems is based on the implementation of some critical tools and practices in order to fulfill the purpose of continuous improvement. Here, performance measurement practices are important since a process can only be improved if it is well mapped, understood and managed and, therefore, measured [4].

In the case of multinational companies, the Supply Chain (SC) is characterized by high complexity, with several internal and external processes and activities being monitored [5], leading to the tendency of developing a large number of performance indicators, which may not benefit the performance management process [6], [7].

Some tools enable to overcome this "over-sized" Performance Measurement System (PMS) issue. As an example, a Composite Indicator (CI) allows the combination of several indicators into a single performance index, summarizing complex and multidimensional realities, promoting its interpretation and the benchmarking process [8]-[10]. Due to it, CIs are becoming more recognized as a useful tool in policy analysis and public communication, being widely applied in the several areas [11] and, most recently, in the quality field [12]. Some studies suggest to adopt the CI approach to analyze tendencies in the manufacturing sector. However, [5] suggested that literature concerning the performance measurement outside companies' boundaries is still limited, being the quality performance measurement of the SC an example.

Following this research opportunity, this research project focused on understanding the potential advantages of using a $\mathrm{CI}$ to measure and manage the SC quality performance. Thus, following the methodologies proposed by [10], [11], this paper purposes a CI to assess the overall performance of the SC processes in terms of efficiency and effectiveness.

\section{LITERATURE REVIEW}

The SC consists of the network used to deliver products and services, from raw materials to the end user, incorporating all the partners, activities, and flows of material and information [13]. According to the Supply Chain Operations Research (SCOR) model, the SC can be summarized in six main processes - Plan, Source, Make, Delivery, Return and Enable [14].

As the SC is becoming the focus of business competition [2], [3], organizations must manage both internal and external operations of their SC, seeking to improve overall performance through the effective use of resources and capabilities [5]. The integrating concept of Supply Chain Quality Management (SCQM) implies the integration of quality and $\mathrm{SC}$ management practices to ensure quality and customer satisfaction along the SC [1].

The adoption of a PMS becomes important since it allows the collection of data from the SC activities necessary to manage and improve SC performance [5]. A PMS is composed by a set of indicators and data that allows the interpretation of the processes performance [4]. The development of performance metrics for the SC can be supported by several frameworks such as the SCOR model [14], which provides a balanced set of measures grouped according to the main SC processes. However, this model has a complex configuration and may imply the definition of a large number of performance metrics [15]-[17], demonstrating the complexity of the SC reality regarding performance management. This issue makes the operationalization of a PMS difficult, since a large amount of measures produces a large and difficult to process amount of information, affecting the evaluation and the decision making processes [7], highlighting the 
need to improve the efficiency of a SC PMS by decreasing its complexity and number of performance measures, making it more concise.

A CI consists in an aggregated index that compiles several individual performance indicators into a single measure. It is a widely applied tool in the social and healthcare areas with similar purposes [18], showing potential to also be applied in the context of a highly complex and multidimensional SC. The development and implementation of CI's have been growing in the past decades [8], as its benefits are well recognized by policymakers and public communication offices, who have been applying this tool both for rapidly interpret and identify tendencies over complex data and to provide more comprehensible information to target audience [11]. Examples of CI are the European Customer Satisfaction Index [19], the Technology Achievement Index [20] or the Human Development Index [21].

Researchers have also proposed the use of CI into the manufacturing sector, more specifically on the analysis of complex nature scenarios such as sustainability [22]-[24], resource efficiency [25]-[27] and competitiveness issues [28]. The increasing popularity of this tool not only can be explained by its capacity in simplifying complex issues, but including the following [11], [18]: (1) It can represent multidimensional realities, supporting decision-makers by offering a rounded assessment performance; (2) A CI is easier to understand and interpret than trying to find trends in a large set of indicators; (3) A CI promotes the efficiency of a PMS, by including more information in a minor set of indicators; (4) It facilitates the spreading of best practices, by promoting the benchmarking process and facilitating the communication.

Although these benefits, the use of $\mathrm{CI}$ is not consensual and examples of non-desired effects of poorly constructed CI include [11], [18]: (1) The possibility to oversimplify a complex issue, increasing the risk of disregard important information; (2) The determination of a root cause for poor performance may be difficult, or even serious failures may be disguised, affected also by poor quality data; (3) It is highly dependent on the weights of each individual indicator and the weighting process does not follow a straightforward methodology.

Such shortcomings can lead to misinterpreted results and conclusions, leading consequently to inappropriate actions. For that reason, several cautions must be taken during the CI design process in order to get the desired benefits. Depending on the situation under analysis, the application field and the strategic objectives, some steps must be carefully adapted, following subjective choices [8], [10]. For example, the aggregation and weighting can be made using several different methods. The selection of the right method is critical since it will affect the quality and reliability of the CI [8], [29].

The development of a CI does not follow a universally applied methodology, but it must include several main steps: (1) Selection of inputs and variables that will compose the CI; (2) Normalization or scaling of the variables, so all the variables can be compared using the same standard; (3) Aggregation and weighting of all inputs, according to their importance for the final calculation; (4) Validation of the final CI, where continued tests, adjustments and improvements are made, providing robust and valid results [10], [11], [30]. Further, it is important to assure the CI transparency and enabling its decomposition into the real data [11].

\section{METHODOLOGY FOR THE DEVELOPMENT OF THE COMPOSITE INDICATOR}

Based on the previous concepts, it is presented the adopted methodology for the development of the CI, following the described recommendations of [10], [11]:

1. The purpose of the CI must be clearly identified: what is intended to be measured, how it is going to be measured and how results should be read and interpreted.

2. The inputs required to calculate the CI must be selected and characterized, such as Key Performance Indicators (KPIs), evidences, policies and other relevant information for the issue to be measured. These inputs can be collected from surveys, expert panel or stakeholder interviews. These must be selected based on importance, accessibility, timeliness and analytical soundness.

3. Since the $\mathrm{CI}$ is supposed to use data from various inputs, it is important to understand how to overcome situations related to missing data, rounded data, or interrelationships data.

4. As the KPIs may be reported in different measurement units, it is necessary to normalize them over the same standard, so they can be compared. Also, as different KPIs have different targets, it is important that an improvement in each KPI may also translate an equivalent improvement in the CI.

5. Since some KPIs may have more impact on the final outcome than others, it is important to reflect this weight in the overall CI. Hence, different weights should be assigned according to the relevance of each KPI, before the aggregation of the data. Different methods can be applied to the weighting process, such as stakeholders' insights, impact on business costs and profitability [10].

\section{CONCEPT VALIDATION}

This research was conducted and applied on a multinational automotive company. Both academic and company's experts were involved in the research team, collaborating along the different stages of the study (from the definition of the research methodology until the implementation and validation of the final $\mathrm{CI}$ ) with the intention to adapt and apply it to other SC processes.

It was decided to apply this methodology to the Return process, due to its lower level of complexity and data accessibility. This process deals with all activities associated with the reverse flow of products from customers to the manufacturer, either by complaints or returned stock [14]. The purpose of the developed CI is to provide an overall insight over the SC performance. In this specific case, the developed concept was named 
Composite Indicator for the Return process (CIR), which in the end should be able to provide a global view of the Return process performance in two different perspectives: efficiency and effectiveness, plot in the same graphic.

The CIR development started with the identification and characterization of all KPIs related to the Return process, resulting in the information shown in the TABLE I. Due to confidentiality agreements, KPIs are designated by numbers (e.g., KPI-1, KPI-2).

For the purpose of concept validation, data sets from the years 2016 and 2017 were collected, on a monthly basis. As the company already assess its performance on a monthly basis, for each KPI it was gathered the monthly results as well as the targets related to that period.

TABLE I. INDIVIDUAL KPIS TO DEVELOP THE CIR

\begin{tabular}{cc}
\hline KPI designation & Measurement Units \\
\hline KPI-1 & $\%$ \\
KPI-2 & PPM \\
KPI-3 & PPM \\
KPI-4 & \%; Time; Quantity; Binary \\
KPI-5 & Euros (€) \\
KPI-6 & Quantity \\
KPI-7 & Quantity \\
\hline
\end{tabular}

After the data collection, some issues related to missing data needed to be discussed. Therefore, the following assumptions were made: (1) When the targets were defined on a yearly basis, they were translated on an equivalent monthly target; (2) For unidentified or unclear targets, it was assumed that the target would be equal to the previous year to date result; (3) When data was not available for a given $\mathrm{KPI} / \mathrm{month}$, it was assumed that the KPI failed the target in that month.

As the selected KPIs are measured in different units not enabling a direct comparison between them, a scoring method was defined to be applied to each KPI, based on the comparison between the monthly achieved result and the respective target. For measuring effectiveness, a binary approach was applied to each KPI: for a given month, if the target is achieved, the KPI is scored as 1, otherwise it is scored as 0 . For measuring efficiency, a scoring method was also defined, calculated by the ratio between the monthly result of the KPI and the respective target, resulting in a percentage (\%) score. A KPI is scored with $100 \%$ or more if it achieves or exceeds the target, otherwise it is scored below $100 \%$.

As an example, assuming that KP-6 had a monthly target of 10 units maximum, and that by end of the month the achieved result was 12 units, the KPI would be scored as 0 regarding effectiveness and in terms of efficiency would be scored with $80 \%$.

In order to assign a weight to each KPI, company's Return process experts and managers were asked to rank each KPI, in a 1 to 10 scale (from least to most important), according to their overall importance and business impact. Then, the relative weight for each KPI was computed through (1). The assigned weights are presented in TABLE II. Although subjective, this participatory method [10], [18], [31] intents to use experts' relevant knowledge and experience in identifying which KPIs translated and have greater impact on the current business strategy and therefore, should currently have greater weight on the CI.

$$
W_{i}=\frac{\text { Weighting of } K P I_{i}}{\sum_{i=1}^{7} \text { Weighting of } K P I}
$$

TABLE II. WEIGHTS OF INDIVIDUAL KPIS

\begin{tabular}{ccc}
\hline $\begin{array}{c}\text { KPI } \\
\text { designation }\end{array}$ & $\begin{array}{c}\text { Weighting } \\
(\mathbf{1}-\mathbf{1 0})\end{array}$ & $\begin{array}{c}\text { Relative weights }\left(\boldsymbol{W}_{\boldsymbol{i}}\right) \\
\mathbf{( \% )}\end{array}$ \\
\hline KPI-1 & 6 & $9.375 \%$ \\
KPI-2 & 10 & $15.625 \%$ \\
KPI-3 & 8 & $12.500 \%$ \\
KPI-4 & 10 & $15.625 \%$ \\
KPI-5 & 10 & $15.625 \%$ \\
KPI-6 & 10 & $15.625 \%$ \\
KPI-7 & 10 & $15.625 \%$ \\
\hline
\end{tabular}

The purpose of the CIR is to obtain insights regarding the effectiveness and efficiency of the Return process. So, the aggregation method was defined in order to get these two results. The CIR effectiveness assesses if the KPIs achieve or not their targets, based on the explained binary approach. The calculation is made as presented by (2):

$$
\text { CIR Effectiveness }=\sum_{i=1}^{n}\left[T_{i}, W_{i}\right]
$$

Where $T_{i}$ can assume the values 0 or 1 , according if the KPI $i$ achieves or not its target, and $W_{i}$ is the relative weight calculated to each of the KPIs (\%).

The CIR efficiency assesses the overall deviation between the KPIs results against their respective targets. It is calculated as showed in (3):

$$
\text { CIR Efficiency }=\sum_{i=1}^{n}\left[\left(1+\Delta_{i}\right) \cdot W_{i}\right]
$$

Where $\left(1+\Delta_{i}\right)$ represents the deviation between the value of the measure $i$ and its respective target (\%).

Tableau analytics [32] was the chosen IT solution for this implementation, since it provides intuitive data visualization and it enables the breakdown of the CIR until raw data for root causes detection.

\section{RESULTS: APPLICATION OF THE CIR}

After collecting the data and computing the CIR using Tableau, the analysis is performed in two levels.

The CIR main dashboard, shown in Fig. 1, includes chart lines that show the CIR performance on a monthly basis. The performance of each individual KPI is also illustrated by a gradient color scheme, comparing the monthly value against the respective target. Green gradients mean that a KPI has achieved (or exceed) its target. Yellow, orange and red are assigned to KPIs that failed the target. 
Fig. 1 shows the evolution of the CIR performance during the year 2016. In general, September 2016 was the month with the best performance, with 6 out of 7 KPIs in a green gradient, meaning that only 1 KPI failed its target. On the other hand, one can point out that May 2016 was one of the lowest performance months in 2016 in terms of efficiency. Only January was lower in terms of effectiveness. The root cause analysis of poor process performance can be done by analyzing the performance of the individual KPIs, using the KPI gradient color scheme. In terms of effectiveness, it can be verified that only 4 out of 7 KPIs achieved their target.

From the remaining KPIs, one is highlighted by a red color, meaning that it failed the target in more than $30 \%$.

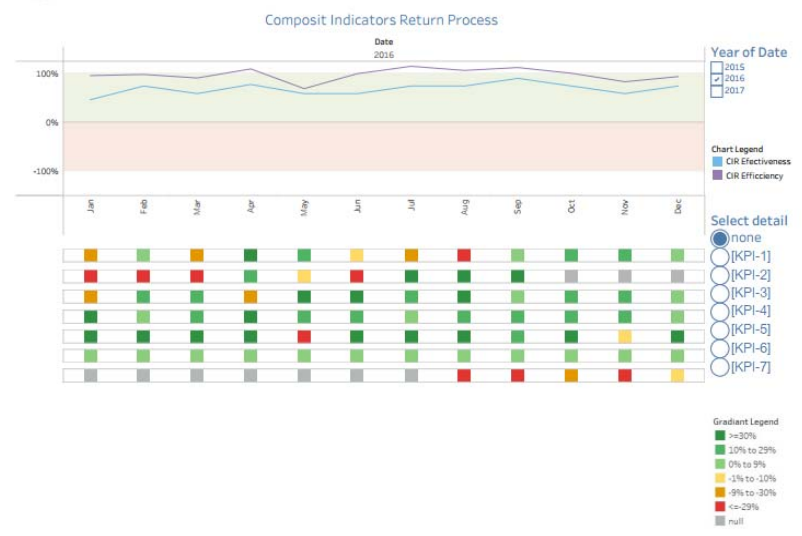

Fig. 1. CIR analysis - global CIR dashboard.

The "level 2 analysis" consists in observing, in a more detailed way, the performance of a specific KPI. By selecting it in the main dashboard, a bar chart is obtained showing its performance, as illustrated in Fig. 2. Following the analysis made before, the "red color" KPI from May 2016 (KPI-5) was selected, and it is possible to confirm that, in that month, it had a poor performance.

For some KPIs, the system can show some more details, by selecting a specific point of the chart. The data can be aggregated in groups, according to the type of analysis required to each KPI (e.g., by customer or type of product). The purpose is to make a deeper analysis of the performance level of a given KPI, in order to better understand the causes of poor performance level.

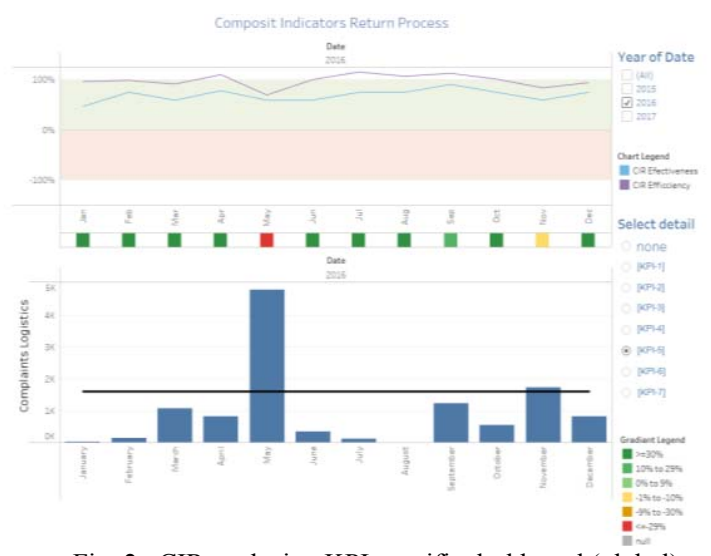

Fig. 2. CIR analysis - KPI specific dashboard (global).
The developed CIR provides a global view of the Return process, allowing to assess the KPIs regarding their targets. Supported by a visual tool, the interpretation of the results is easier and faster, as both line chart and the color gradient scheme promote the detection of the root cause of poor process performance. This methodology proposes a simple procedure to combine existent KPIs, related to the same process into a single analysis and not implying considerable resource consumption.

\section{DISCUSSION}

The involvement of high management and technical experts of the company, particularly in selecting the individual measures and the respective weights, can add additional subjectivity. Given the critical importance of those steps for the quality of the final CI result, it is of vital importance to join an experienced multidisciplinary team to gather technical and empirical knowledge.

However, further research may be followed in order to promote its potential. Also, the next steps should provide answers to the following research questions: (1) What is the relationship between the CIR performance and the business results of the process; and (2) What are the main factors to be considered on how to adapt this methodology to the other SC processes of the company.

Firstly, there is the opportunity to integrate a cost management analysis with the CIR. By integrating a financial KPI of the Return process, the existent correlation between the efficiency and effectiveness indicators and the financial performance of the process can be investigated. Secondly, it is reflected in the objective to develop a CI to measure the performance of all SC processes. For the validated concept described in this paper, further work seeks to adapt this methodology to the remaining SC processes, having their own specific characteristics in consideration.

\section{CONCLUSION}

A CI is a tool used to study complex and multidimensional realities and to communicate results more easily. In an industrial context, the performance measurement of the SC processes and activities can lead to the creation of many performance indicators. The features of a CI show it has the potential to be applied in that context, that was an identified research opportunity.

A methodology for constructing a CI for the SC processes was developed and validated by a concept made for a case study in a manufacturing company on the Return process. Although some precautions are required, the methodology is simple to implement and facilitates the interpretation of data, as well as the identification of root causes of poor performance. However, further research is required in order to understand how to replicate this procedure to the remaining SC processes and to understand its impact on the business results. 


\section{ACKNOWLEDGMENT}

This work has been supported by national funds through FCT - Fundação para a Ciência e Tecnologia within the Project Scope: UID/CEC/00319/2019.

\section{REFERENCES}

[1] A. C. Fernandes, P. Sampaio, M. Sameiro, and H. Q. Truong, "Supply chain management and quality management integration: A conceptual model proposal," Int. J. Qual. Reliab. Manag., vol. 34, no. 1, pp. 53-67, 2017.

[2] L. A. Fish, "Supply chain quality management," in Supply Chain Management-Pathways for Research and Practice, InTech, 2011.

[3] S. T. Foster Jr, "Towards an understanding of supply chain quality management," J. Oper. Manag., vol. 26, no. 4, pp. 461-467, 2008

[4] J. A. Farris, E. M. Van Aken, and G. Letens, "Organizational Performance Measurement," in Handbook of Measurement in Science and Engineering, Hoboken, NJ, USA: John Wiley \& Sons, Inc., 2013, pp. 911-944.

[5] V. Maestrini, D. Luzzini, P. Maccarrone, and F. Caniato, "Supply chain performance measurement systems: A systematic review and research agenda," Int. J. Prod. Econ., vol. 183, pp. 299-315, Jan. 2017.

[6] M. Badawy, A. A. A. El-Aziz, A. M. Idress, H. Hefny, and S. Hossam, "A survey on exploring key performance indicators," Futur. Comput. Informatics J., vol. 1, no. 1-2, pp. 47-52, Dec. 2016.

[7] H. Reisinger, K. S. Cravens, and N. Tell, "Prioritizing Performance Measures Within the Balanced Scorecard Framework," MIR: Management International Review, vol. 43. Springer, pp. 429-437, 2003.

[8] W. Becker, M. Saisana, P. Paruolo, and I. Vandecasteele, "Weights and importance in composite indicators: Closing the gap," Ecol. Indic., vol. 80, pp. 12-22, Sep. 2017.

[9] E. Fusco, "Enhancing non-compensatory composite indicators: A directional proposal," Eur. J. Oper. Res., vol. 242, no. 2, pp. 620-630, Apr. 2015.

[10] M. Mazziotta and A. Pareto, "Methods for Constructing Composite Indices: One for All or All for One? METHODS FOR CONSTRUCTING COMPOSITE INDICES: ONE FOR ALL OR ALL FOR ONE? 1," 2013.

[11] M. Nardo, M. Saisana, A. Saltelli, S. Tarantola, A. Hoffman, and E. Giovannini, "Handbook on Constructing Composite Indicators: Methodology and User Guide," OECD Stat. Work. Pap. OECD Publ., 2005.

[12] P. Saraiva, P. Sampaio, C. Cubo, and M. Reis, "Macroquality measurement: world state of quality and European quality scoreboard approaches and results," Total Qual. Manag. Bus. Excell., pp. 1-17, Apr. 2018

[13] S. Seuring and M. Müller, "From a literature review to a conceptual framework for sustainable supply chain management," J. Clean. Prod., vol. 16, no. 15, pp. 1699 $1710,2008$.

[14] APICS, “SCOR 12.0 Quick Reference Guide," 2017. [Online]. Available: apics.org/docs/default-source/scc-nonresearch/apicsscc_scor_quick reference guide.pdf.

[15] P. Albores, D. M. Love, M. Weaver, and J. Stone, "An evaluation of SCOR modelling techniques and tools," 2006.

[16] F. B. Georgise, K.-D. Thoben, and M. Seifert, "Adapting the SCOR Model to suit the Different Scenarios: A Literature Review \&amp; Research Agenda," Int. J. Bus.
Manag., vol. 7, no. 6, 2012

[17] E. LEPORI, D. DAMAND, and B. BARTH, "Benefits and limitations of the SCOR model in warehousing," IFAC Proc. Vol., vol. 46, no. 9, pp. 424-429, Jan. 2013.

[18] R. Jacobs, P. Smith, and M. Goddard, "Measuring performance: An examination of composite performance indicators CENTRE FOR HEALTH ECONOMICS," York, 2004.

[19] K. Kristensen, A. Martensen, and L. Gronholdt, "Customer satisfaction measurement at Post Denmark: Results of application of the European Customer Satisfaction Index Methodology," Total Qual. Manag., vol. 11, no. 7, pp. 1007-1015, Sep. 2000.

[20] L. Cherchye et al., "Creating composite indicators with DEA and robustness analysis: the case of the Technology Achievement Index," J. Oper. Res. Soc., vol. 59, no. 2, pp. 239-251, 2008.

[21] A. Sen and S. Anand, "Human Development Index Methodology and Measurement," Human Development Report Office, New York, 1994.

[22] S. G. Azevedo, H. Carvalho, L. M. Ferreira, and J. C. O. Matias, "A proposed framework to assess upstream supply chain sustainability," Environ. Dev. Sustain., vol. 19, no. 6 , pp. 2253-2273, Dec. 2017

[23] R. K. Singh, H. R. Murty, S. K. Gupta, and A. K. Dikshit, "Development of composite sustainability performance index for steel industry," Ecol. Indic., vol. 7, no. 3, pp. 565588, Jul. 2007.

[24] L. Zhou, H. Tokos, D. Krajnc, and Y. Yang, "Sustainability performance evaluation in industry by composite sustainability index," Clean Technol. Environ. Policy, vol. 14 , no. 5, pp. 789-803, Oct. 2012.

[25] I. Garcia-Herrero et al., "Measuring the Vulnerability of an Energy Intensive Sector to the EU ETS under a Life Cycle Approach: The Case of the Chlor-Alkali Industry," Sustainability, vol. 9, no. 5, p. 837, May 2017.

[26] S. C. L. Koh, J. Morris, S. M. Ebrahimi, and R. Obayi, "Integrated resource efficiency: measurement and management," Int. J. Oper. Prod. Manag., vol. 36, no. 11, pp. 1576-1600, Nov. 2016

[27] H. Liang, S. Zhang, and Y. Su, "Evaluating the Efficiency of Industrialization Process in Prefabricated Residential Buildings Using a Fuzzy Multicriteria Decision-Making Method," Math. Probl. Eng., vol. 2017, pp. 1-12, Sep. 2017.

[28] H. I. Bilgen and A. Varoglu, "Methodology research of competitiveness and sample application for Turkey's defense industry," Compet. Rev., vol. 26, no. 5, pp. 537558, Oct. 2016.

[29] P. Zhou, B. W. Ang, and D. Q. Zhou, "Weighting and Aggregation in Composite Indicator Construction: a Multiplicative Optimization Approach," Soc. Indic. Res., vol. 96, no. 1, pp. 169-181, Mar. 2010.

[30] F. Booysen, "An Overview and Evaluation of Composite Indices of Development," Soc. Indic. Res., vol. 59, no. 2, pp. 115-151, 2002.

[31] L. Hudrliková, "Composite indicators as a useful tool for international comparison: The Europe 2020 example," Prague Econ. Pap., no. 4, pp. 459-473, 2013.

[32] D. G. Murray and InterWorks team, Tableau Your Data! Fast and Easy Visual Analysis with Tableau Software ${ }^{\circledR}$ Indianapolis: John Wiley \& Sons, Inc., 2013. 